\title{
Paternalistic Leadership and Employees' Sustained Work Behavior: A Perspective of Playfulness
}

\author{
Ching-Han Fang ${ }^{1}$, Ching-Lin Fang ${ }^{2}$, Ren-Fang Chao ${ }^{3, *}$ and Shang-Ping Lin ${ }^{1}$ \\ 1 Department of Business Administration, National Yunlin University of Science and Technology, \\ Yunlin 64002, Taiwan; John.fang@tec-dive.com.tw (C.-H.F.); linsp@yuntech.edu.tw (S.-P.L.) \\ 2 Department of Business Administration, National Chung Cheng University, Chiayi 62102, Taiwan; \\ jackeva59@gmail.com \\ 3 Department of Leisure Management, I-Shou University, Kaohsiung 84001, Taiwan \\ * Correspondence Author: rfchao@isu.edu.tw
}

Received: 17 October 2019; Accepted: 22 November 2019; Published: 25 November 2019

\begin{abstract}
The frontline employees of the service industry are the first connection between enterprises and consumers. Therefore, their performance often represents the image of the company. This study intended to discuss employees' sustained work behavior through the perceived organizational climate, from the point of view of direct supervisors' leadership. Employees of chain convenience stores in Taiwan were used as the research samples for the questionnaire survey. A total of 473 valid questionnaires were considered using structural equation analyses. The results showed that authoritarian leadership and employees' turnover intentions had a significant positive relationship; moreover, there were negative relations between moral leadership, benevolent leadership, and employees' turnover intention. Thus, employees' perceived playfulness can decrease turnover intention when under paternalistic leadership. This study provides valuable insights for managers to understand the work value of playfulness.
\end{abstract}

Keywords: paternalistic leadership; turnover intention; playfulness

\section{Introduction}

The service industry requires more human resources for various services. Although the service process could be standardized, the need for human resources cannot be reduced. In particular, frontline employees play the role of service delivery [1] and maintain the customer relationship and image building for the organization [2]. Frontline employees, therefore, are the key to establishing contact between businesses and customers, as well as the primary connection. An enterprise has to understand how to create a good organizational climate, assist supervisors in using leadership to affect employees, and encourage employees to set goals [3,4] in order to not result in a loss of organizational operation caused by employee turnover [5]. What management model could enhance employees' service quality? Previous research has pointed out supervisors' leadership as the key factor in changing employees' job performance and behavior in the service industry [4,6-8]. Such leadership could promote employees' service quality, as well as enhance the overall service quality of the organization and strengthen team morale. As a result, it has been an important issue for leaders to develop the functioning of the organization so as to enhance employees' job performance and reduce turnover intention. Along with the emergence of the economy in China, a large number of people in the world have become interested in the great Chinese market; therefore, Chinese management has recently been highlighted in management science [9]. The Chinese society, with the effect of traditional culture, is evolving toward a unique appearance, unlike the management theory in the Western world. Under the effects of the traditional Confucianism and monarchy on Chinese culture, people have derived awe 
of "power" [10-12]. In Chinese culture, a leader's power cannot be challenged, and is impressive in that people have to obey their requirements. The idea of "uppers honorable and lowers humble" is therefore deeply implanted in Chinese peoples' minds, who believe that subordinates should do their duty and make an effort to complete tasks assigned by their supervisors. Paternalistic leadership is the representation of leadership theory in Chinese management. On the basis of paternalistic leadership, the relationship between supervisors' leadership and employees' sustained work behavior in the service industry in Taiwan is discussed in this study.

Epitropaki, Kark, Mainemelis, and Lord [13] discovered that employees were aware of the consistency between leaders' behavior and organizational goals. In other words, whether the motivation behind leaders' behavior was self-interested or focused on organizational goals, so then would there be an increase or reduction in their organizational commitment and an influence on their work behavior. Although organizational commitment would affect employees' opinions about organizations, thus further influencing their attitudes and behavior, employees could hardly present an identity when the organizational value is not attractive or shows a low similarity to employees' values. Previous research has indicated that employees with more positive attitudes towards the organization would present a higher job satisfaction [14], as well as restrain individual negative attitudes [15]. Previous research on the service industry has revealed that employees possess the idea of turnover when work focus on their involvement is reduced or they perform badly at their job [5]. A key function of a leader is to effectively deliver organizational value to subordinates, and to further internalize it as a value. The motivation of this study is thus to discuss the relations between supervisors' leadership and employees' sustained work behavior in the service industry.

The organizational climate refers to the group climate in an organization. Such a climate consists of members' mutual interaction, managers' leadership, and organizational culture. With a harmonious and good climate, organizational members would be brought about by positive work motivation. Playfulness refers to the focus on an activity, feeling relaxed and no pressure in the process, enjoying the activity, and being satisfied so as to acquire a sense of achievement $[16,17]$. When a task could stimulate the fun of members to learn and recognize their value, playfulness can more easily occur [18]. Furthermore, playfulness can lead an originally dominant person, in the working process, to integrate into the activity with other members [19] by reducing the distance. Employees in the service industry experience longer working hours than those in other industries and have to communicate and interact with hundreds of people, in addition to their colleagues, every day. Employees can easily affect service quality and job performance as a result of a negative work environment climate $[3,20]$. Compared with other industries, in the service industry, employees' showing a happy mood in that they are enjoying their work increases their willingness to provide better service quality to customers [21]. Supervisors, therefore, should encourage employees to appropriately present themselves at work and maintain a pleasant work environment, as employees with positive feelings can provide better service for their customers $[19,20]$. Moreover, they can encourage employees to lead more creative service processes and integrate them into the organization. Accordingly, the playful organizational climate in the service industry plays a critical role in employees' job performance. A supervisor who is able to create a pleasant and challenging work climate is an advantage for a company in the service industry. The effects of playfulness on the relationship between supervisors' leadership and employees' sustained work behavior in the service industry, therefore, became another research motivation behind this study.

On the basis of the above arguments, this study mainly combined the paternalistic leadership and affective events theory, and focused on the frontline employees of Taiwan's service industry as the research object. Then, we tried to construct and show evidence for the influence of the different forms of paternalistic leadership, and how to affect employees' work behavior. However, to our best knowledge, no prior studies have explored the relationships between perceived playfulness of the paternalistic leadership and employees' work behaviors, the underlying motivational mechanisms, as well as how contextual factors influence such relationships. By identifying perceived playfulness 
and paternalistic leadership that may stimulate employees' underlying motives for work behaviors, our work adds another theoretical route for inducing employee work behaviors, and also contributes to an improved understanding of paternalistic leadership in Chinese management.

\section{Literature Review}

\subsection{Paternalistic Leadership and Employees' Turnover Intention}

Redding [22] analyzed the organizational structure and management styles of Chinese enterprises and considered that the economy and culture in Chinese society were indeed different from Western society and that patriarchy was an important characteristic in Chinese enterprises. The idea of humanity in Confucianism is fundamental for Chinese culture, emphasizing that people have to follow the "honor and humbleness" and "closeness and alienation" during an interaction in order to conform to the spirits of "benevolence", "justice", and "courtesy" in Confucianism. Such a leadership style with the rule of men and patriarchy was found to be common in Chinese enterprises. Researchers, therefore, regarded such a leadership phenomenon as paternalistic leadership [6-8,23,24]. Farh and Cheng [7] defined paternalistic leadership as being under the climate with the rule of men, with a leader presenting leadership styles with strict discipline, father-like benevolence, and a high-standard of moral integrity. They further proposed the following points: (1) authoritarian leadership, emphasizing that the authority is absolute and unchallengeable, that a leader can tightly control subordinates and asks for complete obedience from them; (2) benevolent leadership, where a leader individually, comprehensively, and permanently is concerned about subordinates' welfare; and (3) moral leadership, where a leader should present a higher personal conduct and accomplishment to earn the subordinates' admiration and imitation [25-27].

According to affective events theory, a supervisor's emotion affects subordinates' behavior and further influences their work attitudes [21]. A supervisor's authoritarian leadership behavior induces a more violent and negative emotional reaction in subordinates, in such that a negative emotional reaction might be expanded to affect subordinates' work attitudes. Authoritarian leadership (e.g., without empowerment or less communication) leads subordinates to perceive unfair treatment, and leadership that depreciates subordinates is considered as ignorance, or having a lack of consideration for inducing subordinates' anger and fierce emotional reactions [28,29]. For this reason, subordinates, when perceiving the leaders' authoritarian leadership, show a more negative and fierce emotional reaction. According to the social exchange concept, subordinates who show a drastic emotional reaction because of supervisors' authoritarian leadership behavior reduce the organizational identity and further present adverse behavior toward the organization. Hypothesis 1a is therefore inferred in this study-authoritarian leadership shows positive relations with employees' turnover intention.

The ones with benevolent leadership understand; forgive; and are concerned about, take care of, and support subordinates to cultivate subordinates' positive attitudes and behavior [24,25]. In other words, a leader, in addition to assisting in subordinates' work, is concerned about their life, and provides work and extra support for subordinates. According to the social exchange theory, a leader treats subordinates with reciprocal exchange principles and offers more concern and care for people on their side, including in their work and personal life. The ones with benevolent leadership are further involved in subordinates' personal lives. For Chinese people who stress reciprocity, subordinates consider leaders as people on their side in a disguised form and show an intention to reward leaders. The direct reaction is to conform to leaders' expectations with dedicated job performance and positive attitudes in the workplace. Consequently, Hypothesis $1 \mathrm{~b}$ is inferred in this study-benevolent leadership reveals negative relations with employees' turnover intention.

The main meaning of moral leadership refers to leaders, with personal noble morality and integrity, presenting leadership while not interfering with the personal interests with the job, making no exception, and sacrificing themselves to accomplish the goal [30]. Such leadership induces subordinates' job identity and leads them to agree and internalize the value and the goal of the enterprise. In other 
words, subordinates comprehend the motivation behind the leaders' behavior, form positive attitudes toward the leader, and further reveal their identity and behavior. In this case, when the organizational values are attractive or similar to the subordinates' values, they model the leaders' behavior and agree with the values and goals. Accordingly, Hypothesis $1 \mathrm{c}$ is inferred in this study-moral leadership presents a negative relationship with employees' turnover intention.

\subsection{Moderating Effects of Playfulness}

Playfulness refers to people that conduct a certain activity that involves large effort without external goals, forgetting other affairs, and feeling integration with the activity and situation $[17,18]$. Playfulness does not need extra rewards other than getting great pleasure and a sense of achievement in the process and is the awareness of integration [17]. Employees in an organization with strong playfulness are willing to make extra effort in exploring new ideas [31], promoting learning with colleagues in the teamwork process [19]. Playfulness is a funny and humorous climate perception; therefore, excessive playfulness behavior may result in negative effects, whereas an appropriate level of playfulness creates a vital work climate; induces employees' increased learning motivation and creativity $[16,32,33]$; and enhances social interaction, releases discouragement and pressure, and improves teamwork and participation to further promote job performance.

Csikszentmihalyi [18] discovered that playfulness more easily occurs when intrinsic motivation can be established and a goal can be set at work. $\mathrm{Yu}, \mathrm{Wu}, \mathrm{Chen}$, and Lin [34] described playfulness as the tendency to extract immediate pleasure from the activity, and to integrate that into the activity. Proyer, Gander, Bertenshaw, and Brauer [35] pointed playfulness out as a personal trait. When the work task of a person was to play, the interaction should be discussed individually, as personality affects work attitudes and performance. When the work was regarded as a task, the working efficiency declined, which increased the working hours for the task. When finding fun at work or in the learning context, work imagination and involvement is enhanced. The so-called work playfulness is the autonomous, imaginary, and emotional expression, as well as funny and enjoyable attitudes presented at work or in the learning experience, to enhance individual job and creativity performance, resulting in job satisfaction and a positive feeling.

Previous research indicated that employees increase work creativity and involvement when having fun in a working or learning context $[16,17,33]$. So-called work playfulness is the autonomous, imaginary, and emotional expression, as well as funny and enjoyable attitudes presented at work or in the learning experience, done to enhance individual job and creativity performance, and resulting in job satisfaction and a positive feeling [21,35]. For this reason, it is considered in this study that a higher level of playfulness results in stronger, autonomous, in-depth involvement and focus, a feeling of self-satisfaction and enjoyment, and feeling relaxation with released pressure and a changed mind. Such perception results in inspiration, creativity, and an unexpected good performance. On the contrary, employees in a negative organizational climate have less interaction and cannot acquire a sense of achievement at work. Research has revealed that employees start to have the idea of turnover when they are unsatisfied with their work. It is therefore considered, in this study, that when employees' interaction is reduced and they do not learn, with each other, to induce better creativity in an organization, they present low satisfaction at work and have a stronger turnover idea. As a result, the following hypotheses are proposed in this study:

H1a: Higher playfulness weakens positive relations between authoritarian leadership and employees' turnover intention.

H1b: Higher playfulness enhances negative relations between benevolent leadership and employees' turnover intention.

H1c: Higher playfulness enhances negative relations between moral leadership and employees' turnover intention. 


\section{Method}

\subsection{Participants and Procedure}

Employees of chain convenience stores in Taiwan were selected for this study. A total of 580 employees volunteered to participate in the study, and a questionnaire survey was implemented twice, with paper tracking. A total of 531 employees completed the questionnaire in the first stage; the questionnaire included questions exploring paternalistic leadership, turnover intention, and demographic statistics. The second stage of the survey was implemented two weeks later. On the basis of the employees' responses in the first stage, the actual questionnaire was implemented to explore playfulness, and a total of 512 employees responded to the questions. There were 39 employees that were excluded, as they were employed for less than six months, and a total of 473 samples were considered to be valid. Of the participants, $72.8 \%$ were female, the average age was $24.37,88.9 \%$ of them were college students and above, and their average experience was 3.28 years.

\subsection{Measures}

We referred to Cheng et al.'s [6] study, consisting of 15 items for 3 dimensions, which were measured with a Likert five-point-scale ( 1 for extremely disagree, and 5 for extremely agree) for paternalistic leadership. In this study, we used the confirmatory factor analysis (CFA) test scales' construct validity $(\mathrm{CV})$ and composite reliability (CR). An example item for the authoritarian leadership is "I would be severely punished by not following the supervisor's principles". The CR in authoritarian leadership was 0.944 , and its internal consistency reliability Cronbach's $\alpha$ was 0.925 . The CFA results showed that the mode fit was good $\left(\chi^{2}=944.23, \mathrm{df}=95, \chi^{2} / \mathrm{df}=9.94, \mathrm{CFI}\right.$ (Comparative Fit Index) $=0.97$, NFI $($ Normed Fit Index $)=0.96$, RMSEA (Root Mean Square Error of Approximation) $=0.09$ ). An example item for benevolent leadership is "My supervisor would help me solve difficulties in life". The CR in benevolent leadership was 0.851 , and its internal consistency reliability Cronbach's $\alpha$ was 0.833 . The CFA results showed that the mode fit was good $\left(\chi^{2}=849.61, \mathrm{df}=72, \chi^{2} / \mathrm{df}=11.80, \mathrm{CFI}=0.95\right.$, $\mathrm{NFI}=0.94$, and RMSEA $=0.09$ ). An example item for moral leadership is "My supervisor is a good model for dealing with affairs and people". The CR in moral leadership was 0.917 , and its internal consistency reliability Cronbach's $\alpha$ was 0.892 . The CFA results showed that the mode fit was good $\left(\chi^{2}=895.74, \mathrm{df}=87, \chi^{2} / \mathrm{df}=10.30, \mathrm{CFI}=0.96, \mathrm{NFI}=0.95\right.$, and RMSEA $\left.=0.09\right)$.

Referring to Michaels and Spector [36], three items were used to measure the employee's intention of leaving the work, using a five-point Likert scale ( 1 for extremely disagree, and 5 for extremely agree), for the turnover intention. Two of them are, "I have the idea to leave current work", and "I might leave my current work for another arrangement". With the sum mean, the higher scores present the higher employees' turnover intention. The CR in authoritarian leadership was 0.897 , and its internal consistency reliability Cronbach's $\alpha$ was 0.884 . The CFA results showed that the mode fit was good $\left(\chi^{2}=862.39, \mathrm{df}=88, \chi^{2} / \mathrm{df}=9.80, \mathrm{CFI}=0.96, \mathrm{NFI}=0.95\right.$, and RMSEA $\left.=0.08\right)$.

Referring to the adult playfulness scale proposed by Yu et al. [34], five dimensions with 33 items were used to measure employees' perceived organizational playfulness, with a five-point Likert scale ( 1 for extremely disagree, and 5 for extremely agree). For instance, teamwork is free and open, without being restrained; supervisors manage employees with less control, but more support; there is more criticism and less support among colleagues; and it is not necessary to dress formally for work. Playfulness is a firm level variable, and we used a second-order single-factor model for the CFA. The confirmatory factor analysis also revealed a good goodness of fit $\left(\chi^{2}(396)=428.835, p<0.001\right.$, GFI $($ Goodness of Fit Index $)=0.931$, TLI (Tucker-Lewis index $)=0.924$, CFI $=0.927$, RMSEA $=0.055$, SRMR (Standardized Root Mean Square Residual $)=0.058$ ) of the second-order playfulness. The Cronbach's $\alpha$ of playfulness was found as 0.903 . 


\section{Result}

Table 1 shows the mean, standard deviation, and correlation coefficient of the variables, among which there are significant correlations.

Table 1. Means, standard deviations, and inter-correlations among focused variables.

\begin{tabular}{cccccccc}
\hline Variables & $\mathbf{M}$ & SD & $\mathbf{1}$ & $\mathbf{2}$ & $\mathbf{3}$ & $\mathbf{4}$ & $\mathbf{5}$ \\
\hline 1. Authoritarian leadership & 2.72 & 0.82 & $(0.833)$ & & & & \\
2. Benevolent leadership & 3.23 & 0.73 & $-0.211^{*}$ & $(0.892)$ & & & \\
3. Moral leadership & 3.66 & 0.68 & $-0.236^{* *}$ & $0.268^{* *}$ & $(0.925)$ & & \\
4. Playfulness & 3.41 & 0.77 & $-0.241^{* *}$ & $0.257^{* *}$ & $0.294^{* *}$ & $(0.884)$ & \\
5. Turnover intention & 2.91 & 0.92 & $0.281^{* *}$ & $-0.232^{* *}$ & $-0.264^{* * *}$ & -0.0292 & $(0.903)$
\end{tabular}

Note. $n=472 ;{ }^{*} p<0.050,{ }^{* *} p<0.010$; M refers to the mean of focus variables; SD refers to the standard deviation of focus variables; Cronbach's $\alpha$ is in parentheses on the diagonal.

In this study, M-plus 8 was utilized for the structural equation model analyses so as to test the direct and indirect effects of the paternalistic leadership and playfulness on employees' turnover intention. The hypothesized model using confirmatory factor analysis exhibited a good fit to the data, as shown in Table 2. The five-factor model (chi-square $=2499.57, \mathrm{df}=475 ; \mathrm{CFI}=0.92, \mathrm{NFI}=0.92, \mathrm{IFI}=0.91$, RMSEA $=0.05$, SRMR $=0.05$ ) significantly outperformed the single-factor and 12-factor models. The five-factor model includes authoritarian leadership, benevolent leadership, moral leadership, playfulness, and turnover intention. Figure 1 shows the significant positive effects of authoritarian leadership on turnover intention $(\gamma=0.292, p<0.01)$; therefore, H1a was supported. Benevolent leadership presented significant negative effects on turnover intention $(\gamma=-0.254, p<0.01)$; therefore, $\mathrm{H} 1 \mathrm{~b}$ was supported. Moral leadership revealed significant negative effects on turnover intention $(\gamma=-0.271, p<0.01)$; therefore, H1c was supported. In the moderating effect analysis of playfulness, it was discovered that playfulness moderated the relations between authoritarian leadership $(\gamma=0.221$, $p<0.01)$, benevolent leadership $(\gamma=-0.281, p<0.01)$, and moral leadership $(\gamma=-0.305, p<0.001)$, and turnover intention.

Table 2. Results of the discriminative validity by confirmatory factor analysis (CFA).

\begin{tabular}{ccccccccc}
\hline Model & $\chi^{\mathbf{2}}$ & df & $\chi^{\mathbf{2}} / \mathbf{d f}$ & CFI & NFI & IFI & RMSEA & SRMR \\
\hline 12-factor model & 3413.16 & 461 & 7.40 & 0.82 & 0.85 & 0.88 & 0.06 & 0.06 \\
Five-factor model & 2499.57 & 475 & 5.26 & 0.92 & 0.92 & 0.91 & 0.05 & 0.05 \\
Single-factor model & 4764.82 & 483 & 9.87 & 0.51 & 0.48 & 0.67 & 0.16 & 0.12 \\
\hline
\end{tabular}

Note: ${ }^{*} p<0.05,{ }^{* *} p<0.01$; the single factor model is combined with all factors in one; the five-factor model is combined with playfulness and all other factors in one. CFI: Comparative Fit Index; NFI: Normed Fit Index; IFI: Incremental Fit Index; RMSEA: Root Mean Square Error of Approximation; SRMR: Standardized Root Mean Square Residual.

The simple slope analysis of the moderating effects. When there was high playfulness, it was revealed that the positive effect of authoritarian leadership on turnover intention was significantly reduced ( $\beta=0.21, p<0.05$ ), the positive effect of benevolent leadership on turnover intention was significantly enhanced $(\beta=0.25, p<0.01)$, and the positive effect of moral leadership on turnover intention was significantly enhanced $(\beta=0.28, p<0.01)$ when playfulness was high. When playfulness was low, the positive effect of authoritarian leadership on turnover intention was significantly reduced $(\beta=0.18, p<0.05)$, the positive effect of benevolent leadership on turnover intention was significantly enhanced $(\beta=0.21, p<0.05)$, and the positive effect of moral leadership on turnover intention was significantly enhanced $(\beta=0.22, p<0.05)$. Accordingly, $\mathrm{H} 2 \mathrm{a}, \mathrm{H} 2 \mathrm{~b}$, and $\mathrm{H} 2 \mathrm{c}$ were supported. As shown as Figures 2-4, when employees were in situations of high playfulness, their turnover intentions were lower than low playfulness. As shown in Figure 2, when the level of perceived playfulness was high, the positive relationship between authoritarian leadership and turnover intention was significant; when 
the level of perceived playfulness was low, the positive relationship between authoritarian leadership and turnover intention was also significant. This suggests that employees' turnover intention had a stronger effect on their supervisor's authoritarian leadership when they perceived a higher degree of playfulness; when the perceived level of playfulness was high, the effect of turnover intention on authoritarian leadership behaviors became weaker. Similarly, as Figure 3 shows, when the level of perceived playfulness was high, the negative relationship between benevolent leadership and turnover intention was strengthened; when the level of perceived playfulness was low, the negative effect of turnover intention on benevolent leadership was lessened. As displayed in Figure 4, when the level of perceived playfulness was high, the employees' turnover intention had a strong negative effect on moral leadership; when the level of perceived playfulness was low, the negative relationship between moral leadership and turnover intention was also lessened.

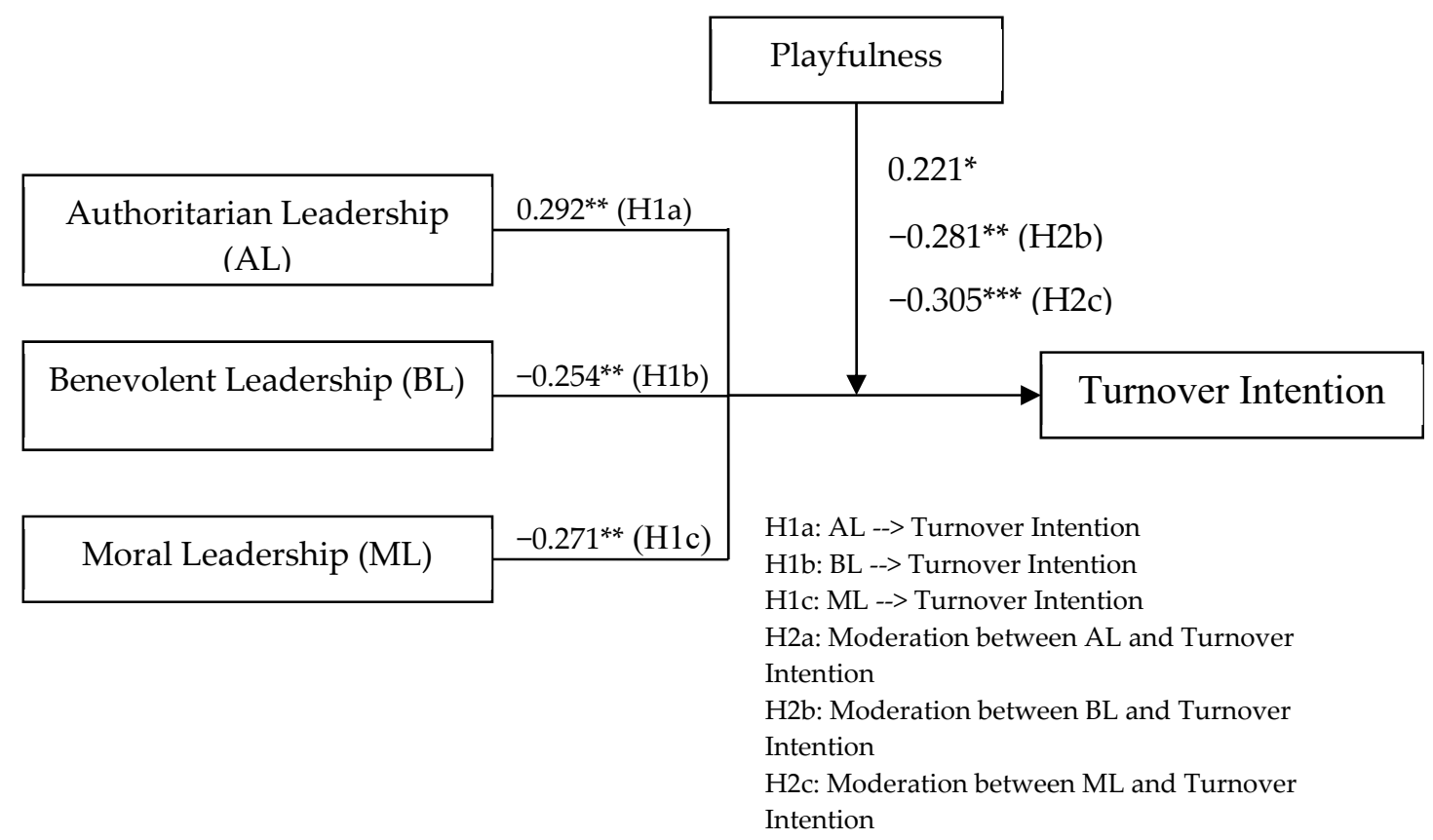

Figure 1. Results of the structural model analyses with standardized path coefficients ${ }^{*} p<0.050$, $\left.{ }^{* *} p<0.010,{ }^{* * *} p<0.001\right)$.

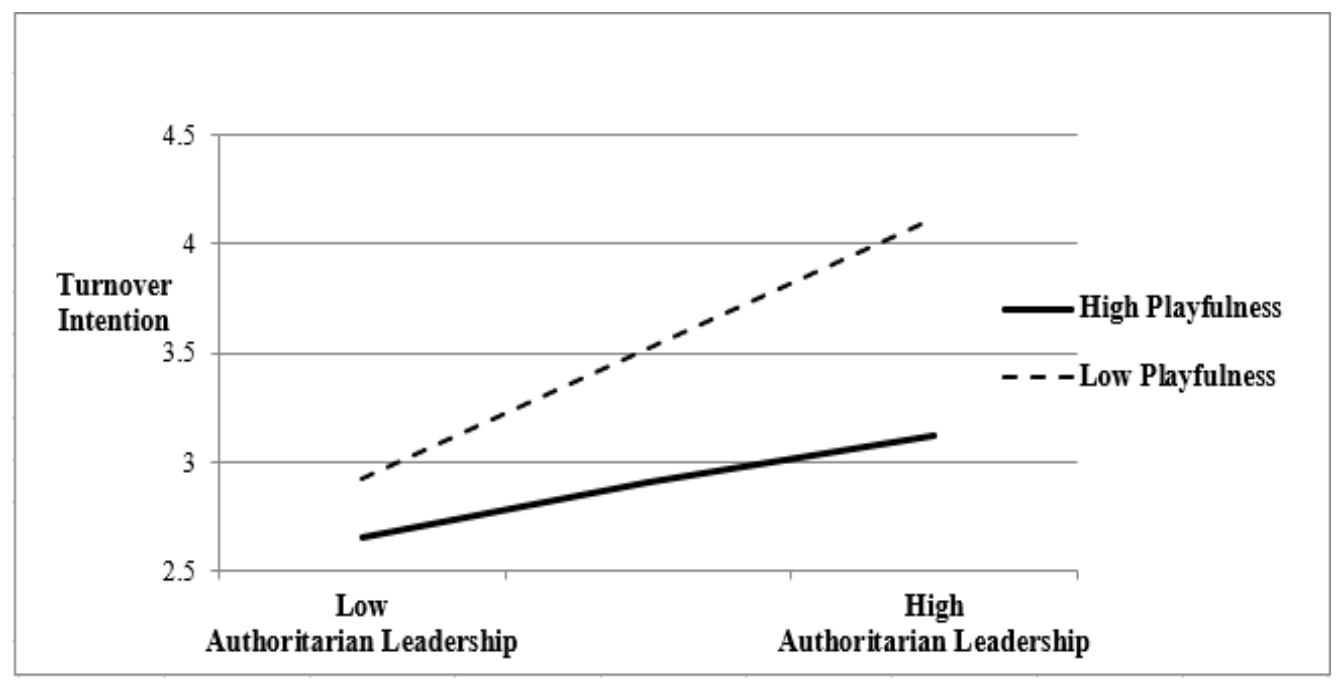

Figure 2. Moderating effect of playfulness on authoritarian leadership and turnover intention. 


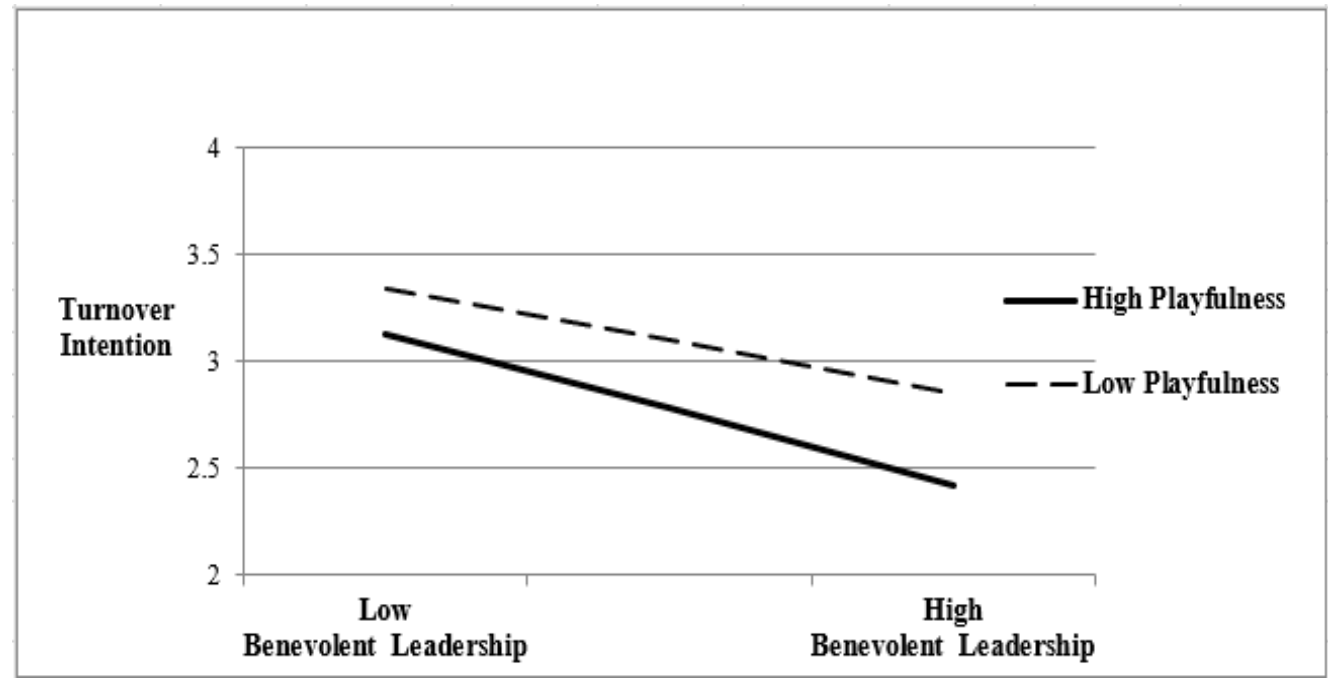

Figure 3. Moderating effect of playfulness on benevolent leadership and turnover intention.

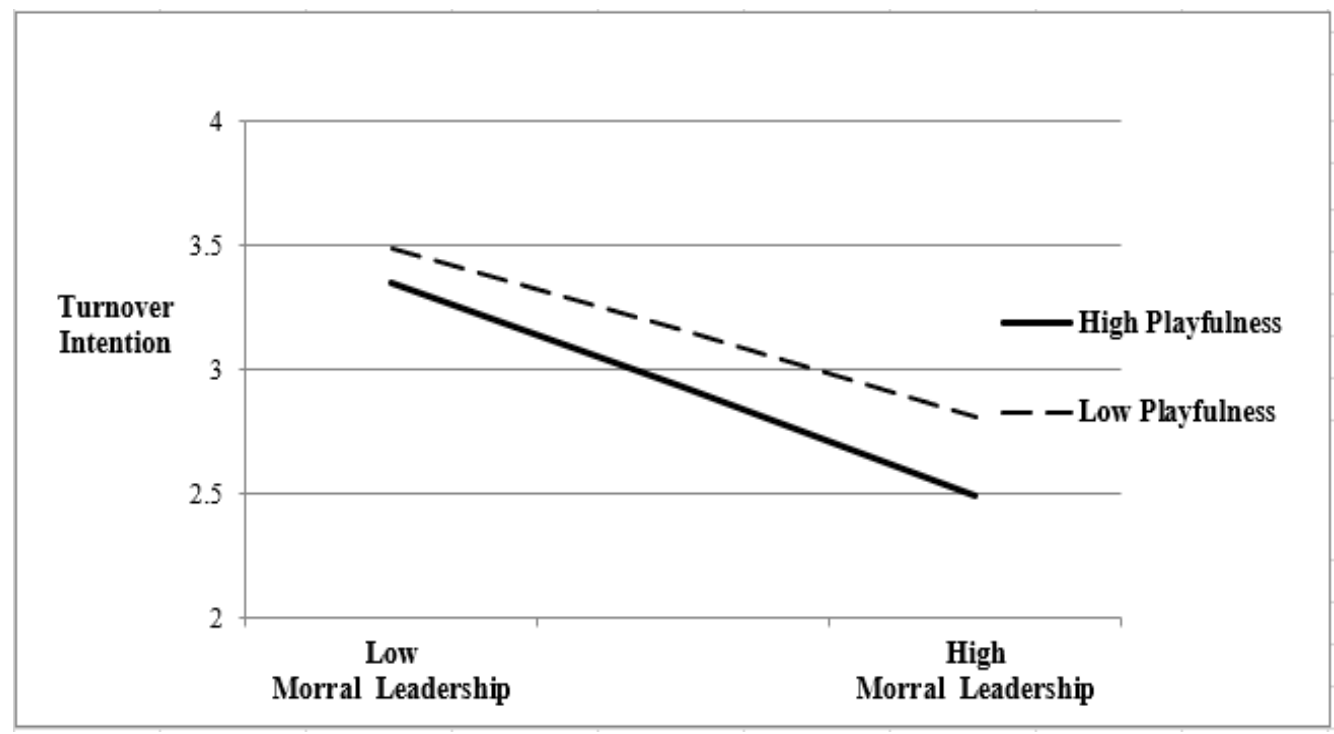

Figure 4. Moderating effect of playfulness on moral leadership and turnover intention.

\section{Discussion}

The research findings and conclusions are organized in this section according to the previous research results, expecting to offer managers a reference for future practice, with research limitations and future suggestions being further proposed.

In the results that we found, there was a positive relationship between authoritarian leadership and employees' turnover intention. It was found that when a supervisor is autocratic, strictly controlling subordinates and depreciating subordinates' abilities, one can end up with employees worrying about being blamed for making mistakes or not achieving the expected goals of their work content or performance, and they further develop evasive ideas $[6,8,29]$. Such evasive ideas could easily lead to the development of negative emotions and could generate negative behaviors, such as laziness or turnover intention. Therefore, organizations should avoid excessive authoritarian leadership to reduce the negative behavior of employees who are not conducive to organizational development. We also found that it revealed negative relations between supervisors' benevolent leadership and employees' turnover intention. This is the same finding as in previous studies $[7,28,30]$. When a supervisor in the service industry is concerned about subordinates' lives and helps them to solve the difficulties in their lives, employees perceive the attentiveness to enhance the relationship. Moreover, 
a supervisor who is able to build a good work atmosphere can increase employees' work efficiency and reduce their turnover intention. Finally, moral leadership and employees' turnover intention presents a negative relationship $[27,30]$. When a supervisor is responsible and shows a high morality, employees will trust them to gradually form a new corporate culture in the organization, and this will benefit the retaining of excellent employees. In summary, managers play an important and relatively stable role in the organizational life of employees, and their influence on employees is sustainable and profound. This is because leadership style can predict the performance of the organization, and managerial beliefs and behaviors can significantly affect employees' attitudes and behaviors [37,38]. Furthermore, the research results revealed the moderating effect of playfulness on the relationship between paternalistic leadership and turnover intention. It is an important finding that playfulness can reduce the positive relationship between authoritarian leadership and turnover intention. Those with authoritarian leadership present an autocratic style and harm communication, and this can also depreciate subordinates, causing unsatisfactory interactions and information asymmetry. All of these will deepen subordinates' negative perception. However, when there is a higher playfulness perception in an organization, employees can work in harmony in the work atmosphere. Also, because the work is joyful, this will restrain employees' negative behavior. Playfulness can strengthen negative relations between benevolent leadership, moral leadership, and employees' turnover intention (shown in Figures 3 and 4). Thus, with higher playfulness perception in an organization, and a good relationship between direct supervisors and subordinates, supervisors empathize with employees and respect and support employees' decisions within their obligation and responsibility. In this case, employees will be willing to stay at the organization to reduce their turnover intention. With the content of "carrot and stick" in paternalistic leadership, a leader cannot regard authoritarian leadership as the measure of controlling subordinates, but presenting morality or benevolent leadership behavior can cause the subordinates to perceive the difference in the upper and lower relationship, as well as showing kindness and selfless integrity as they would with family. Benevolent leadership and moral leadership are important paradigms of Chinese management. According to the social learning theory, these two forms of leadership provide a good model for employees' learning, and can motivate employees' identification and gratefulness at the same time.

\section{Conclusions}

\subsection{Practical Implications}

In the face of the impacts of modernization and globalization, traditional Chinese authoritarian leadership should be changed. Subordinates are no longer affected by traditional legalism to present obedient behavior in response to supervisors' authoritarian leadership. This study provides a reflection opportunity for management practice, showing that the traditional Chinese power structure is changing when facing diversified subordinates. The content of paternalistic leadership can be described as carrot and stick, showing that when an unchallengeable authority is presented, father-like instruction and care will also be displayed. It is therefore suggested in this study that, in addition to controlling subordinates with authoritarian leadership, a leader should apply benevolent leadership or moral leadership behavior to release subordinates' violent emotional reactions caused by authoritarian leadership, as well as to reduce the emotional reaction time. Benevolence and morality are emphasized by Chinese people and are the methods used to protect people from being persecuted by the power abuse of hierarchy; earning people, by virtue, is an effective method to have subordinates agree with and imitate their leaders. Previous research has suggested that supervisors' moral leadership behavior, such as justice and selflessness, integrity, probity, honesty, and being a model, could earn subordinates' identity and imitation. Accordingly, it is suggested in this study that supervisors' value should match the organizational value, and the organizational value should be actually delivered to subordinates when presenting the integrity and selflessness. Furthermore, assistance in solving difficulties, provision 
of growth and development opportunities, and timely encouragement enhance subordinates' positive effects on their organization.

The work characteristics of the service industry are different from other industries (e.g., shift system for the arrangement of vacation, longer working hours, labor-intensive nature, and being irreplaceable by machine). In this case, employees in the service industry have to serve various customers, in addition to getting along with colleagues, during the long working periods in the organization. The entire organizational climate, therefore, is extremely important for employees in the service industry, and could easily affect their behavior. It is therefore suggested in this study that the service industry should create good organizational playfulness, assist the employees in the suitable development in the organization, encourage healthy competition among colleagues, and provide proper resources for employees' learning. Appropriate humor, exchange of ideas, and no criticism in the interaction with colleagues can better ensure employees' innovation for the service process. On the other hand, when the service industry does not offer favorable organizational playfulness for employees, supervisors with benevolence and moral leadership can facilitate employees to stay at the organization so as to decrease employee turnover and further reduce organizational costs.

\subsection{Limitations and Suggestions}

Supervisors' leadership and organizational playfulness in the service industry were discussed in this study, but other factors, such as job satisfaction and working pressure, were not considered; therefore, their effects were ignored. Furthermore, a leader has to face the ups and downs in relationships (with supervisors and subordinates), as well as peer-pressure and expectation. In particular, Chinese people stress that a personal and private relationship, in addition to the relationship in the organization, is also expected [11,12]. Research also indicates that an individual with a higher perceived role of conflict shows a higher turnover intention, higher job burnout, and even reduced job satisfaction. This study discussed the correlations between leadership and organizational commitment from the perspective of subordinates, but not from leaders' points of view. It is suggested that successive research should explore the relationship between leadership and employees' sustained work behavior from the perspective of supervisors, by utilizing a paired questionnaire survey. Moreover, variables specific in Chinese society (e.g., guanxi culture, renqing, and mianzi) could be included to discuss Chinese people's organizational behavior.

Author Contributions: For research articles with several authors, a short paragraph specifying their individual contributions must be provided. The following statements should be used "Conceptualization, C.-H.F. and R.-F.C.; Methodology, C.-H.F.; Software, C.-L.F.; Validation, C.-H.F., C.-L.F. and R.-F.C.; Formal Analysis, C.-L.F.; Investigation, C.-L.F.; Resources, R.-F.C.; Data Curation, C.-L.F.; Writing-Original Draft Preparation, C.-H.F.; Writing-Review \& Editing, R.-F.C.; Visualization, R.-F.C.; Supervision, S.-P.L.; Project Administration, S.-P.L.; Funding Acquisition, S.-P.L.".

Funding: This research received no external funding.

Acknowledgments: The authors are grateful to the valuable comments made by the editor and reviewers.

Conflicts of Interest: The authors declare no conflict of interest.

\section{References}

1. Kaminakis, K.; Karantinou, K.; Koritos, C.; Gounaris, S. Hospitality servicescape effects on customer-employee interactions: A multilevel study. Tour. Manag. 2019, 72, 130-144. [CrossRef]

2. Bowen, D.E. The changing role of employees in service theory and practice: An interdisciplinary view. Hum. Resour. Manag. Rev. 2016, 26, 4-13. [CrossRef]

3. Hui, C.H.; Chiu, W.C.K.; Yu, P.L.H.; Cheng, K.; Tse, H.H.M. The effects of service climate and the effective leadership behaviour of supervisors on frontline employee service quality: A multi-level analysis. J. Occup. Organ. Psychol. 2007, 80, 151-172. [CrossRef]

4. $\mathrm{Wu}, \mathrm{T}$; $\mathrm{Wu}$, Y.J.; Tsai, H.; Li, Y. Top Management Teams' Characteristics and Strategic Decision-Making: A Mediation of Risk Perceptions and Mental Models. Sustainability 2017, 9, 2265. [CrossRef] 
5. Arnoux-Nicolas, C.; Sovet, L.; Lhotellier, L.; Di Fabio, A.; Bernaud, J.-L. Perceived Work Conditions and Turnover Intentions: The Mediating Role of Meaning of Work. Front. Psychol. 2016, 7, 704. [CrossRef] [PubMed]

6. Cheng, B.-S.; Chou, L.-F.; Wu, T.-Y.; Huang, M.-P.; Farh, J.-L. Paternalistic leadership and subordinate responses: Establishing a leadership model in Chinese organizations. Asian J. Soc. Psychol. 2004, 7, 89-117. [CrossRef]

7. Farh, J.-L.; Cheng, B.-S. A Cultural Analysis of Paternalistic Leadership in Chinese Organizations. In Management and Organizations in the Chinese Context; Palgrave Macmillan: London, UK, 2000; pp. 84-127.

8. Hou, B.; Hong, J.; Zhu, K.; Zhou, Y. Paternalistic leadership and innovation: The moderating effect of environmental dynamism. Eur. J. Innov. Manag. 2019, 22, 562-582. [CrossRef]

9. Hwang, K.K. Confucian relationalism and social exchange. In Foundations of Chinese Psychology; Springer: New York, NY, USA, 2012.

10. Hwang, K.-K. Face and Favor: The Chinese Power Game. Am. J. Sociol. 1987, 92, 944-974. [CrossRef]

11. Wu, T.-J.; Tsai, H.-T.; Yeh, S.-P. The Role of manager's Locus of Control between perceived guanxi and leadership behavior in family Business. Rev. Int. Sociol. 2014, 72, 87-104. [CrossRef]

12. Wu, T.-J.; Yuan, K.-S.; Yen, D.C.; Xu, T. Building up resources in the relationship between work-family conflict and burnout among firefighters: Moderators of guanxi and emotion regulation strategies. Eur. J. Work Organ. Psychol. 2019, 28, 430-441. [CrossRef]

13. Epitropaki, O.; Kark, R.; Mainemelis, C.; Lord, R.G. Leadership and followership identity processes: A multilevel review. Leadersh. Q. 2017, 28, 104-129. [CrossRef]

14. Schuh, S.C.; Egold, N.W.; Van Dick, R. Towards understanding the role of organizational identification in service settings: A multilevel study spanning leaders, service employees, and customers. Eur. J. Work Organ. Psychol. 2012, 21, 547-574. [CrossRef]

15. Liao, S.-H.; Widowati, R.; Hu, D.-C.; Tasman, L. The mediating effect of psychological contract in the relationships between paternalistic leadership and turnover intention for foreign workers in Taiwan. Asia Pac. Manag. Rev. 2017, 22, 80-87. [CrossRef]

16. Hung, S.-Y.; Tsai, J.C.-A.; Chou, S.-T. Decomposing perceived playfulness: A contextual examination of two social networking sites. Inf. Manag. 2016, 53, 698-716. [CrossRef]

17. Zhou, F.; Wang, N.; Wu, Y.J. Does university playfulness climate matter? A testing of the mediation model of emotional labour. Innov. Educ. Teach. Int. 2019, 56, 239-250. [CrossRef]

18. Csikszentmihalyi, M. Finding Flow: The Psychology of Engagement with Everyday Life; Basic Books: New York, NY, USA, 1997.

19. Su, F.; Cheng, D.; Wen, S. Multilevel Impacts of Transformational Leadership on Service Quality: Evidence From China. Front. Psychol. 2019, 10, 1252. [CrossRef]

20. Ling, Q.; Lin, M.; Wu, X. The trickle-down effect of servant leadership on frontline employee service behaviors and performance: A multilevel study of Chinese hotels. Tour. Manag. 2016, 52, 341-368. [CrossRef]

21. Wu, T.J.; Wu, Y.J. Innovative work behaviors, employee engagement, and surface acting: A delineation of supervisor-employee emotional contagion effects. Manag. Decis. 2019, 57, 3200-3216. [CrossRef]

22. Redding, S.G. The Spirit of Chinese Capitalism; Walter de Gruyter: Berlin, Germany, 1990.

23. Pye, L.W.; Pye, M.W. Asian Power and Politics: The Cultural Dimensions of Authority; Harvard University Press: Cambridge, MA, USA, 1985.

24. Lee, J.Y.; Jang, S.H.; Lee, S.Y. Paternalistic leadership and knowledge sharing with outsiders in emerging economies: Based on social exchange relations within the China context. Pers. Rev. 2018, 47, 1094-1115. [CrossRef]

25. Gu, Q.; Tang, T.L.P.; Jiang, W. Does moral leadership enhance employee creativity? Employee identification with leader and leader-member exchange (LMX) in the Chinese context. J. Bus. Ethics 2015, 126, 513-529. [CrossRef]

26. Tuan, L.T. Driving employees to serve customers beyond their roles in the Vietnamese hospitality industry: The roles of paternalistic leadership and discretionary HR practices. Tour. Manag. 2018, 69, 132-144. [CrossRef]

27. Qin, X.; Huang, M.; Hu, Q.; Schminke, M.; Ju, D. Ethical leadership, but toward whom? How moral identity congruence shapes the ethical treatment of employees. Hum. Relat. 2018, 71, 1120-1149. [CrossRef]

28. Dedahanov, A.T.; Bozorov, F.; Sung, S. Paternalistic Leadership and Innovative Behavior: Psychological Empowerment as a Mediator. Sustainability 2019, 11, 1770. [CrossRef] 
29. Liang, S.-G. Linking leader authentic personality to employee voice behaviour: A multilevel mediation model of authentic leadership development. Eur. J. Work Organ. Psychol. 2017, 26, 434-443. [CrossRef]

30. Zhang, Y.; Huai, M.-Y.; Xie, Y.-H. Paternalistic leadership and employee voice in China: A dual process model. Leadersh. Q. 2015, 26, 25-36. [CrossRef]

31. Proyer, R.T. Development and initial assessment of a short measure for adult playfulness: The SMAP. Pers. Individ. Differ. 2012, 53, 989-994. [CrossRef]

32. Ekvall, G. Organizational climate for creativity and innovation. Eur. J. Work Organ. Psychol. 1996, 5, $105-123$. [CrossRef]

33. Pinchover, S. The Relation between Teachers' and Children's Playfulness: A Pilot Study. Front. Psychol. 2017, 8, 2214. [CrossRef]

34. Yu, P.; Wu, J.-J.; Chen, I.-H.; Lin, Y.-T. Is playfulness a benefit to work? Empirical evidence of professionals in Taiwan. Int. J. Technol. Manag. 2007, 39, 412-429. [CrossRef]

35. Proyer, R.T.; Gander, F.; Bertenshaw, E.J.; Brauer, K. The Positive Relationships of Playfulness with Indicators of Health, Activity, and Physical Fitness. Front. Psychol. 2018, 9, 1440. [CrossRef]

36. Michaels, C.E.; Spector, P.E. Causes of employee turnover: A test of the Mobley, Griffeth, Hand, and Meglino model. J. Appl. Psychol. 1982, 67, 53-59. [CrossRef]

37. Mihai, L.; Schiopoiu, A.B.; Mihai, M. Comparison of the leadership styles practiced by Romanian and Dutch SME owners. Int. J. Organ. Leadersh. 2017, 6, 4-16. [CrossRef]

38. Burlea-Schiopoiu, A.; Rainey, S. Servant leader/Servant leadership. In Encyclopedia of Corporate Social Responsibility; Idowu, S.O., Capaldi, N., Zu, L., das Gupta, A., Eds.; Springer-Verlag: Berlin/Heidelberg, Germany, 2013; pp. 2120-2126.

(C) 2019 by the authors. Licensee MDPI, Basel, Switzerland. This article is an open access article distributed under the terms and conditions of the Creative Commons Attribution (CC BY) license (http://creativecommons.org/licenses/by/4.0/). 